\title{
Gold tailings as a source of waterborne uranium contamination of streams - The Koekemoerspruit" (Klerksdorp goldfield, South Africa) as a case study Part II of III: Dynamics of groundwater-stream interactions
}

\author{
Frank Winde* and Izak Jacobus van der Walt
}

North West University, School of Environmental Sciences and Management, Private Bag X6001, Potchefstroom 2520, South Africa

\begin{abstract}
Dissolved uranium (U) from the tailings deposits of various gold mines in South Africa has been found to migrate via seepage and groundwater into adjacent streams. The extent of the associated non-point pollution depends on the concentration of $U$ in the groundwater as well as the volume and rate of groundwater seepage into the stream channel. Whilst the U concentration in groundwater is relatively constant and comparatively easy to determine, the same is not true for the flux of groundwater into the stream. In order to track the water exchange at the groundwater-stream interface, real-time in situ measurements by data-logger controlled probes for gauging heights and electrical conductivity (EC) were taken at $10 \mathrm{~min}$ intervals. As a result of a steep hydraulic gradient between water-saturated tailings deposits and the receiving watercourse, exfiltration (base-flow) of contaminated groundwater generally dominates. However, short-term inversions of the flow direction (infiltration of stream water into the groundwater) were also observed. These are attributed to an artificial flow regime of the Koekemoerspruit, which results from a pumping scheme that discharges groundwater from underground mine workings into the stream. Differences in pumping rates lead to pronounced diurnal fluctuations of gauging heights in the stream, which in turn cause even higher fluctuations of the associated groundwater table. The hydraulic mechanisms of the stream-groundwater interaction, as well as implications for the aqueous transport of $\mathrm{U}$ are discussed.
\end{abstract}

Keywords: hydrodynamics, waterborne U transport, hydraulic groundwater-stream interaction, real-time in situ measurements, hydraulic gradient, base-flow, infiltration, streamflow, pumping scheme, diurnal fluctuations

\section{Introduction}

Due to elevated concentrations of $U$ and other heavy metals in tailings deposits of gold and $U$ mines, seepage from such deposits often leads to diffuse contamination of nearby watercourses. The dissolved metals migrate into the underlying groundwater and eventually seep into the adjacent stream (Winde, 2003). The extent of such non-point pollution systems depends on the concentrations of dissolved contaminants in the groundwater, as well as the volume and rate of groundwater seepage into the stream. Referring to the study area as described in Winde et al. (2004a) this paper explores the dynamics of hydraulic interactions (hydrodynamics) between the shallow (alluvial) groundwater and the stream.

Since pore water in tailings deposits usually forms a phreatic surface that is often located several tens of meters above the water level in adjacent watercourses, hydraulic gradients result which drive subsurface seepage-flow from tailings towards the stream. The associated non-point stream pollution by exfiltration of contaminated groundwater is usually regarded as a continuous process of more or less constant intensity throughout the year. Fig. 1 illustrates the hydraulic gradients between the Koekemoerspruit and two adjacent sources of diffuse stream pollution.

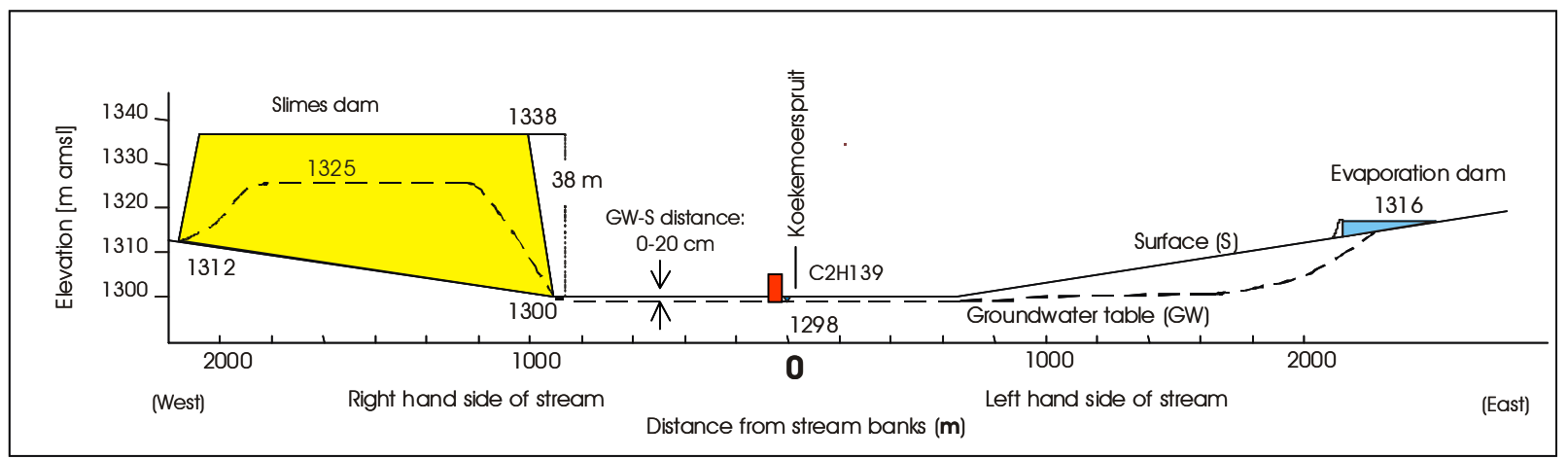

Figure 1

\# The Afrikaans word "spruit" can be translated as a creek or small stream.

* To whom all correspondence should be addressed.

面+2718 787 4435; fax:+2718 7875972; e-mail: Frank.Winde@goldfields.co.za Received 1 July 2003; accepted in revised form 10 February 2004.

Hydraulic gradient between the Koekemoerspruit and the nearest slimes dam on the right hand side (west) and between the evaporation dam on the left hand side (east) 




By measuring gauging heights in the Koekemoerspruit and the associated alluvial aquifer at 10 min intervals using data-logger controlled piezometric probes in groundwater monitoring pipes, the dynamics of hydraulic interactions between surface water and groundwater were tracked over a period of two years.

\section{Study area}

The study area is described in Winde et al. (2004a) and entails the lower portion depicted in Fig. 2 of the mentioned reference, between the Buffelsfontein slimes dams and evaporation dam.

\section{Methods}

All data were recorded by a computerised data-logging station installed at a gauging weir $\mathrm{C} 2 \mathrm{H} 139$. In addition to sensors used for tracking hydraulic interactions between stream and groundwater (based on measurements of gauging heights and electrical conductivity), probes for measuring hydro-chemical $(\mathrm{pH}, \mathrm{Eh})$, physical (water temperature) and meteorological parameters (air temperature, relative humidity and precipitation) were also installed. All sensors were wired to and controlled by a data-logger of the type Delta T, Dl2e (Fig. 2).

Gauging heights in the alluvial aquifer were measured in a groundwater-monitoring pipe (PET, $80 \mathrm{~mm}$ in diameter, $0.2 \mathrm{~mm}$ slashed), which was installed at a depth of $1 \mathrm{~m}$ in the floodplain sediments, $15 \mathrm{~m}$ from the eastern bank (right hand side) of the stream. To protect the instruments from vandalism, a cap of bricks (500 mm x $500 \mathrm{~mm}$ wide, $400 \mathrm{~mm}$ high) was built around the top of the pipe. Water levels in the Koekemoerspruit were measured in a gauging-well inside of the monitoring station C2H139 by a piezometer recording gauging heights at $10 \mathrm{~min}$ intervals. The same instrument was used in the groundwater-monitoring pipe allowing measurements in the range of 10 to $900 \mathrm{~mm}$ height of water column. Both piezometers were re-calibrated monthly. Simultaneously, the electrical conductivity (EC) at both locations was measured at identical time-intervals using temperature-compensated sensors (reference temperature: $25^{\circ} \mathrm{C}$ ). Rainfall was meas- ured at 10 min intervals by an electronic pluviometer installed on top of the gauging hut (approximately $2 \mathrm{~m}$ above ground), which was also connected to the data-logger inside the hut. Rainwater running through the pluviometer was collected in a $3 \ell$ PET-bottle inside the gauging hut for evaluating the pluviometer records (volume) and for collecting samples. Air temperature and relative air humidity were also electronically recorded by sensors placed on top of the hut.

\section{Results and discussion}

\section{Flow regime in the Koekemoerspruit}

Gauging records of the Koekemoerspruit display pronounced diurnal and weekly fluctuations of the water level (between 200 and $500 \mathrm{~mm} /$ day), which is mainly caused by the pumping scheme at the Margaret shaft. Because of cheaper off-peak prices of electricity, the pumping rates at night and during weekends are significantly higher than in daytime during the week; $435 \mathrm{l} / \mathrm{s}$ and $160 \mathrm{l} / \mathrm{s}$ respectively (De Bruin, 2000).

The diurnal cycle of flow reaches a maximum of $435 \ell / \mathrm{s}$ during night-time (22:00 to 06:00), when electricity is less expensive and all (seven) pumps are operating. During daytime only three pumps are employed, pumping an average of $160 \mathrm{l} / \mathrm{s}$ into the Koekemoerspruit (De Bruin, 2000). The varying flow rate results in water level changes at the gauging weir, ranging from a minimum of about $200 \mathrm{~mm}$ to a maximum of $500 \mathrm{~mm}$. The water level at the weir peaks about 23 to $24 \mathrm{~h}$ after switching to the maximum pumping rate (22:0 to 23:00). With a vertical distance of $1.3 \mathrm{~km}$ from the underground level to the surface at Margaret shaft and another $15 \mathrm{~km}$ of horizontal distance from there to the gauging station, an average flow velocity of approximately $0.2 \mathrm{~m} / \mathrm{s}$ results. The minimal flow at the gauging weir occurs at about noon (11:30 to 13:00). During weekends (Friday 22:00 to Monday 06:00) the reduced electricity price applies, resulting in an often uninterrupted high flow rate. Since no water is extracted for industrial purposes, streamflow at weekends is in general even higher than the maximum flow rates during the week (Fig. 3). 




Figure 3

Pumping scheme-related streamflow fluctuations at the Koekemoerspruit (example: period 1 - 20 June 2000) (Su - Sunday; lines indicating 0:00 hours)
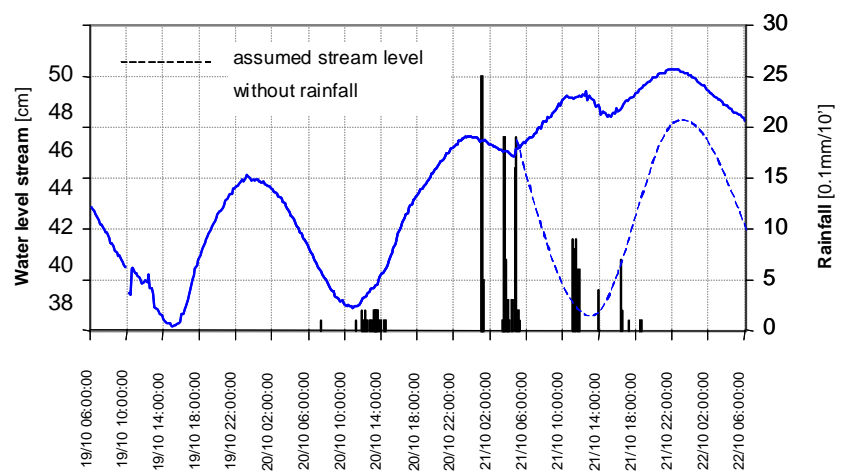

Figure 4

Responses of the water level in the Koekemoerspruit to rain events

When increasing seepage into the mine void during wet seasons exceeds the storage capacity of the underground reservoirs at Margaret shaft, maximum pumping rates are also applied during daytime (De Bruin, 2000).

Due to the pumping scheme, rain events in the catchment do not result in a typical hydrograph but often only smooth out diurnal fluctuations (Fig. 4).

Since rainwater also recharges the dolomitic aquifer from which seepage trickles down into the mining void, a delayed impact on the streamflow is observed, resulting from higher pumping rates at the Margaret shaft for several days after the rain event.

\section{Hydraulic interaction between stream and alluvial groundwater}

Time series of the gauging height in the stream and the alluvial groundwater level are similar, suggesting a close hydraulic link between the two water bodies (Fig. 5).

Statistical time-series analyses using the software STATISTIKA were carried out to check whether the visual relation is also consistent over time. Shifting one of the time series along the time scale, the best correlation $(\mathrm{R}=0.75$ ) occurred when the groundwater series was lagged against that of the stream by $3 \mathrm{~h}$. This compares favourably to the chart analysis, which yielded an average time lag between the maxima of both time series of $3 \mathrm{~h}$ (Fig. 6).

Applying a Boskop transformation to ignore variations in the amplitude of changes, the correlation between the stream level and the variation in groundwater gauging heights improved to $\mathrm{R}=0.93$ (95\% confidence level) (De Beer, 2000).

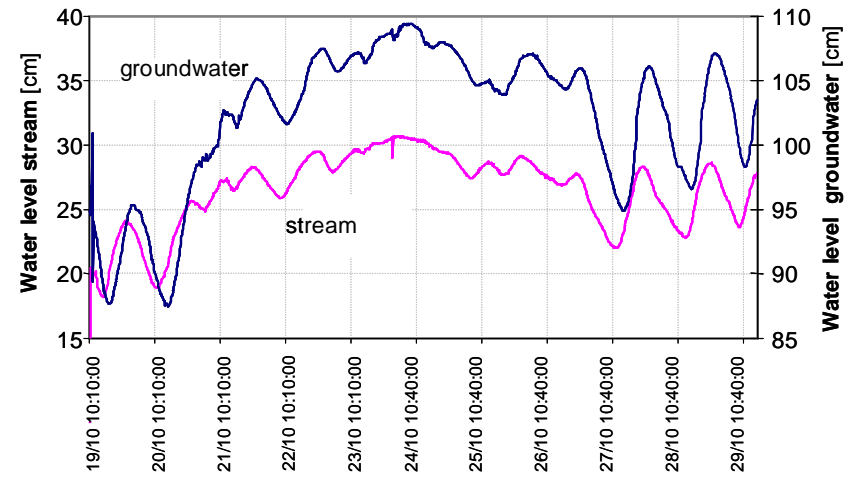

Figure 5

Gauging heights in the Koekemoerspruit and the associated groundwater level (observation period 19 - 29 October 1999)
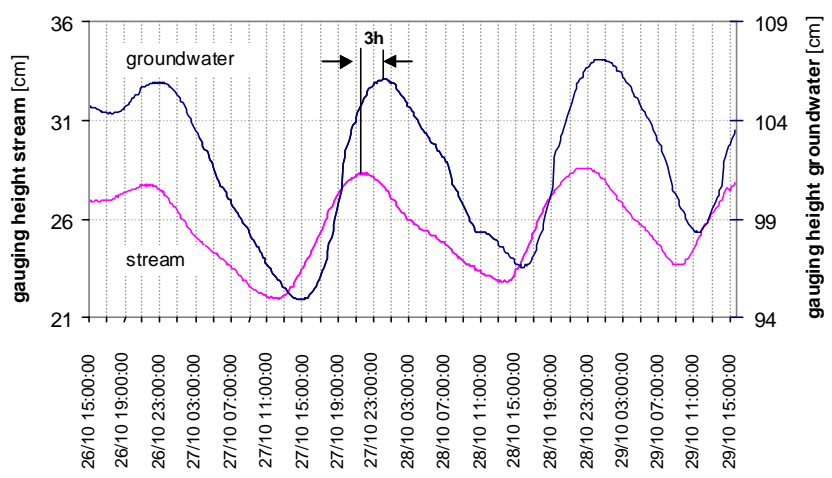

Figure 6

Time-delay of the groundwater response to streamflow fluctuations in the Koekemoerspruit

Attempts to find any significant dependency of the diurnal groundwater fluctuations on relative air humidity (as an inverse indicator for evapotranspiration) failed. It can therefore be concluded that the pumping-related flow variations in the Koekemoerspruit are the most important (if not the only) cause for the pronounced diurnal fluctuations of the associated groundwater table in the adjacent floodplain. The close statistical relationship was further confirmed by correlating the maximal daily differences in gauging heights of both water bodies. For a period of $12 \mathrm{~d}$ (19 - 30/10/1999) a strong linear regression with $\mathrm{R}=0.9867$ (95\% confidence level, $n=12$ ) between the series was found. The resulting fit of:

Groundwater level $[\mathrm{mm}]=1.79$ x stream level $[\mathrm{mm}]-0.89$

indicates that the response of the alluvial groundwater to streamflow oscillations is not only delayed by $3 \mathrm{~h}$ but also amplified by a factor of 1.79. Thus, an increase in the stream-level of $100 \mathrm{~mm}$ causes the groundwater table to rise by $179 \mathrm{~mm}$. The ratio between the gauging height changes in the groundwater and the stream will be referred to in the Discussion as the "amplification-factor". The amplified response of the groundwater table to stream level changes is mainly due to the space that is taken up by sediments in the floodplain. These cause infiltrating stream water to rise higher than it does in the (sediment-free) stream channel. This suggests that the amplification-factor is determined only by the pore volume of the floodplain sediments (which in turn depends on their grain size distribution). Since for practical purposes the grain size distribu- 




Figure 7

Examples of calculated hydraulic gradients at the Koekemoerspruit indicating infiltration and exfiltration

(= base-flow)

tion of the sediments can be regarded as constant over time (although clay minerals may change their size according to the moisture content), no significant temporal changes of the amplification-factor are to be expected. However, it was found that the amplification-factor varied considerably within the period observed. For December 1999 an average amplification-factor of 5.35 was measured (compared to 1.79 in October) with stream fluctuations of 40 to $150 \mathrm{~mm} / \mathrm{d}$ causing groundwater fluctuations of 100 to $800 \mathrm{~mm} / \mathrm{d}$.

The major difference between the two months was the significantly higher gauging heights (flow rates) in December, which were almost twice as high as those in October (400 to $500 \mathrm{~mm}$ instead of 200 to $300 \mathrm{~mm}$ ). It is assumed therefore that in addition to the pore volume of sediments, the stream level (flow rate) also influences the amplification-factor. However, no significant linear relationship between stream level and amplification-factor could be established. The reason for this might be that rising gauging heights in the stream channel are associated with an exponential (non-linear) increase of streamflow (as reflected in a typical rating curve). Assuming that the flow rate rather than the water level actually impacts on the amplification-factor, it is likely that the latter behaves similar to the water level - flow relation, i.e. rising with increasing gauging heights and asymptotically approaching a maximum.

Apart from the pore volume of the alluvial sediments and flow rate in the stream, the amplification-factor is also influenced by rain events, with runoff superimposing stream - groundwater interactions. Due to significant time-differences in the hydraulic response between the stream and groundwater to the same event, relationships between stream level and amplification factor are further complicated. While runoff into the stream causes a quick increase of stream levels, the percolation of rainwater through the unsaturated zone into the groundwater takes much longer. Owing to such time differences, the correlation between fluctuations of stream and groundwater levels decreased from $\mathrm{R}=0.9867$ for the 'dry' October period to $R=0.9037(n=4320)$ for December 1999, where a number of rain events occurred.

\section{Water flow at the stream-groundwater interface (hydraulic gradient)}

\section{Dynamics of groundwater-stream interactions}

The direction and rate of water flow between the stream and the alluvial aquifer are determined by the hydraulic conductivity of sediments at the groundwater-stream interface and the hydraulic gradient between both water tables. With the hydraulic conductivity of sediments largely constant, the flow rate depends exclusively on the hydraulic gradient, which indicates direction and rate of water flow between the two systems. It can be calculated as the quotient of the height difference between stream and the groundwater table and the distance between the points of height gauging (Fig. 7). Therefore, negative values indicate flow of groundwater into the stream (= exfiltration or base-flow conditions) and positive values of the hydraulic gradient indicate infiltration of stream water into the alluvial groundwater.

Using gauging height time series of the stream-water and the groundwater respectively, the hydraulic gradient was calculated for each 10 min interval over a period of seven months. The resulting third time series indirectly reflects the water flow (hydrodynamics) between stream and groundwater in high temporalresolution. An example is given in Fig. 8, which displays a twoweek period in November 1999 where, after low-intensity rainfall on the $7^{\text {th }}$ and $8^{\text {th }}$, dry weather conditions prevailed.

As shown in Fig. 9 under those conditions the water flow between the groundwater and the stream reverses daily from exfiltration to infiltration. This distinct diurnal rhythm allows contaminated groundwater, somewhat surprisingly, only during high flow conditions at night-time to infiltrate into the stream channel, while under low-flow conditions during the reverse process prevails (Fig. 9). The reason for the paradox behavior of groundwater to infiltrate only when stream levels are high, is the amplified groundwater response to increased flow rates in the stream, which causes water levels in the floodplain to rise faster than in the stream channel, thereby eventually reversing the hydraulic gradient. 
However, time series of the hydraulic gradient over a sevenmonth period(October - April) indicate that base-flow or exfiltration is the predominant process during the rainfall season (Fig. 10). The data gap between the end of December and end of February was caused by high groundwater levels, which exceeded the measuring scale of the piezometer. This implies that groundwater levels during this period were exceptionally high (>1 $100 \mathrm{~mm})$ so that it is likely that base-flow conditions prevailed during this period. This might have been interrupted by short peak flows during flood events, which may have reversed the direction of water flow temporarily.

The effect of peak flow after rain is uncommon in the lower Koekemoerspruit, since man-made flow fluctuations in the stream have a significantly higher impact on the stream-groundwater interaction than rain events. This is mainly due to the relatively small contribution of rainwater runoff in comparison to the pumped water volume and due to the fact that the former often smoothes streamflow fluctuations (Fig. 10). The latter implies that not only intensity and volume of rainfall determines hydrodynamics in the stream, but also the point in time where the rain event takes place. That means, whilst rainfall during the day only compensates for the flow-drop caused by decreasing pumping rates, it may cause peakflow conditions at night-time when the effects of maximum pumping rates are superimposed.

In addition to this it is likely that seasonal changes in the vegetative cover of the floodplain will also influence hydraulic stream-groundwater interactions by modifying rates of water consumption, transpiration and interception.

\section{Mechanisms of groundwater-stream interactions}

Apart from fluctuating stream levels, resulting in ex- or infiltrating conditions, the absolute value of the hydraulic gradient (steepness) might also have an impact on the stream- and groundwater interactions. During October 1999 and April 2000, the average hydraulic gradient was $+0.4 \%$, suggesting that infiltration was dominant during this period. However, the negative median (central value) of $-0.1 \%$ indicates that more than half of the 11871 values were negative, suggesting that base-flow conditions prevailed. The positive average mainly results from extremely high peaks of positive gradients in November and December during several flood events. With maxima of up to $+5.9 \%$ such peaks are significantly higher than the steepest base-flow gradients (-1.9\%).

A question arising from this is whether very steep hydraulic gradients actually allow stream water to infiltrate far into the adjacent floodplain or whether the diurnal turn-around just recharges "old" stream water back into the stream channel? To assess this, the hydraulic conductivity of the floodplain/bank sediments have to be taken into account. Assuming that stream water could migrate over the whole distance of $15 \mathrm{~m}$ (from the stream to the groundwater monitoring-pipe) during daytime (10 h), a transmission constant (Kf-value) of $4.2 \times 10^{-4} \mathrm{~m} / \mathrm{s}$ would result. Compared to transmission constants given for floodplain sediments $\left(10^{-6} \ldots 10^{-8} \mathrm{~m} / \mathrm{s}\right.$, Mattheß and Ubell, 1990), this is two orders of magnitude higher. Based on the latter the stream water could only infiltrate several tens of millimetres into the bank sediments. This makes it unlikely that stream water physically reaches the groundwater in the monitoring pipe. Rather, it would seem that stream water seeps from the channel through coarser sediments at the bottom of the floodplain (sand, gravel) and recharges the alluvial groundwater from beneath. Very similar EC-charts of stream- and groundwater suggest that the stream water does reach the groundwater-monitoring pipe. It is, however, also possible that infiltrated stream water is 'stored' in bank sediments (bank-stor-

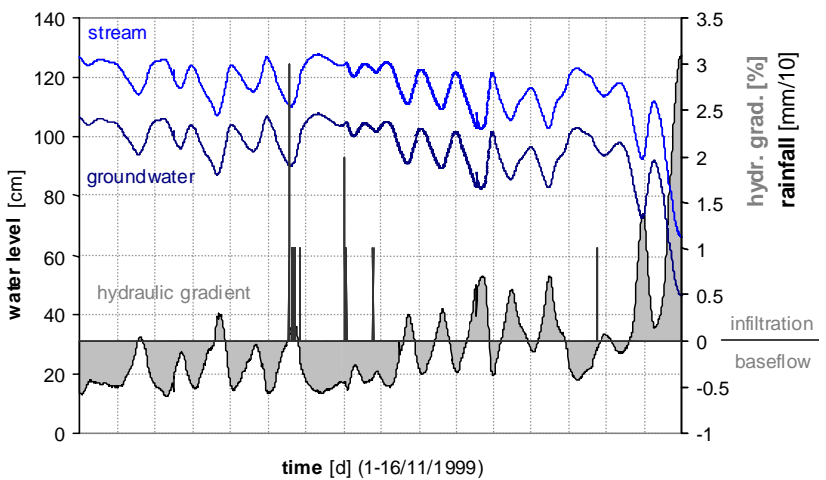

Figure 8

Hydraulic gradient during a 2 weeks period in November 1999

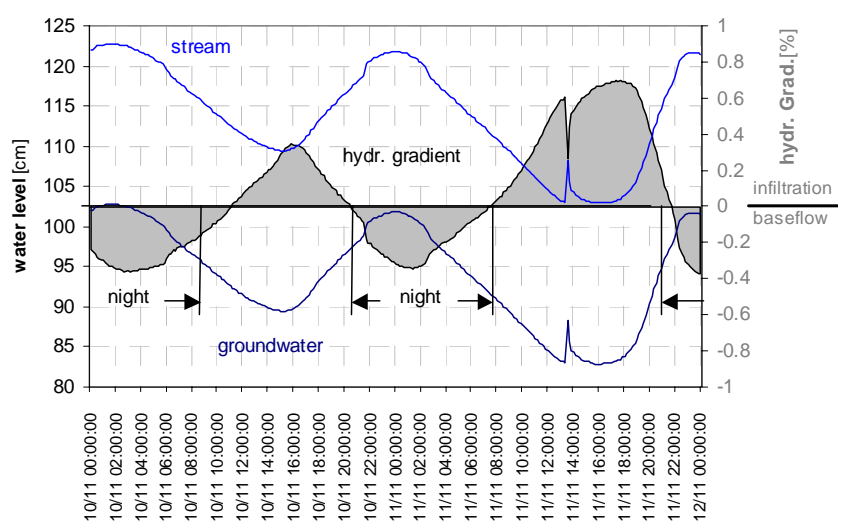

Figure 9

Hydraulic gradient between groundwater and Koekemoerspruit (observation period: 10 - 12 November 1999)

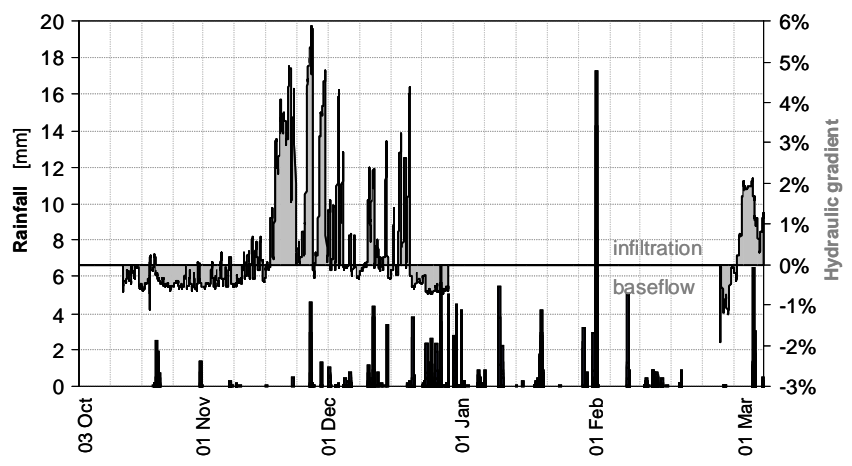

Figure 10

Hydraulic gradient at the Koekemoerspruit in relation to rainfall (observation period: 03 Oct 1999 to 06 Apr 2000)

age) and impedes groundwater flowing towards the stream. Thereby a hydraulic link is formed, which in a kind of a seesaw-effect transmits level changes in the stream to the groundwater pipe in the floodplain. When the water level in the stream drops again, the bank-storage flows back into the channel and allows the impeded groundwater to exfiltrate into the stream.

In general, it seems that strong positive hydraulic gradients are able to temporarily prevent exfiltration of contaminated groundwater, but do not allow stream water to penetrate deep into the floodplain. Since stream level fluctuations are amplified and the groundwater table therefore always rises faster and higher than the stream, ultimately base-flow conditions dominate even during 
periods of pronounced streamflow fluctuations. Because of the low hydraulic conductivity of the floodplain's respective bank sediments, dominance over time seems to be more important than the actual value (steepness) of the hydraulic gradient.

\section{Implications for the transport of $U$ along the aqueous pathway}

\section{Stream contamination}

Since alluvial groundwater is a major source of diffuse pollution of the Koekemoerspruit, the diurnal reversal of water flow between the stream and the alluvial aquifer implies a daily cycle of contamination. Owing to an artificial flow regime, contaminated groundwater can only seep into the stream during the night when increasing water levels trigger an even higher rise of the associated groundwater. This is likely to result in higher concentrations of dissolved $U$ and other heavy metals to occur in stream water at night. Apart from possible effects on benthic and other aquatic organisms this may also affect downstream users.

\section{Floodplain contamination}

Beside the possible consequences for stream contamination, the fluctuating groundwater levels are also likely to affect the transportation of dissolved U through the floodplain sediments. Along with the rising and falling groundwater table, the redox-potential of the floodplain sediments periodically changes between reducing conditions (when submerged) and oxidising conditions (when dry). By redox-initiated co-precipitation of insoluble iron hydroxides and manganese oxides, dissolved $U$ is frequently removed from the groundwater and immobilised in sediments. Considering the low adsorption of $U$ found in floodplain sediments, this process is likely to be the major mechanism for immobilising $U$ in the alluvial sediments. It particularly affects the unsaturated zone of the sediment column, which is repeatedly affected by groundwater table fluctuations.

\section{Monitoring}

The daily rhythm of water-borne stream pollution at the Koekemoerspruit also has implications for the current monitoring programme of the Department of Water Affairs and Forestry, which relies entirely on water samples taken during daytime on a fixed schedule. In this particular case, the actual stream water pollution is unlikely to be detected unless the sampling protocol is changed. Since many other active gold-mines are also operating in dolomitic areas (e.g. the Carletonville area as well as the East Rand), with similar pumping schemes for dewatering of underground mine workings, artificial flow regimes such as in the Koekemoerspruit are likely to be found in streams all over the dolomitic gold-mining areas of South Africa. Thus, current set-ups of (expensive) monitoring programmes should be reconsidered and modified according to local circumstances.

\section{Summary and conclusions}

Gold-mining activities in the study area directly affect the water quality of the Koekemoerspruit and modify hydraulic conditions. Mining-related modifications include the alteration of the natural flow regime and an artificial elevation of groundwater levels in the associated floodplain through inflow of contaminated seepage from adjacent slimes dams.
Using real time in situ measurements, close hydraulic links between the stream and the alluvial groundwater in the adjoining floodplain could be established. Although the steep hydraulic gradient between the slimes dams and the stream determines the general direction of water flow (resulting in dominating exfiltration or base-flow), the reverse process also takes place. During dry periods, the direction of water flow between stream and groundwater reverses on a daily basis. This is caused by pronounced diurnal fluctuations of the streamflow, which results in magnified fluctuations of up to $900 \mathrm{~mm}$ per day in the associated groundwater table. These hydraulic fluctuations determine the extent of water-borne stream pollution and are likely to cause diurnal pulses of dissolved $\mathrm{U}$ and other heavy metals in the stream. Furthermore, the effects of diurnal fluctuations of the stream chemistry are superimposed on this dynamic, as analysed in Winde et al. (2004b).

In addition to impacts on the stream, the artificial flow regime also affects the contamination of floodplain sediments. Periodic changes in the elevation of the associated groundwater table lead to redox-initiated co-precipitation of $U$ along with hydrous oxides of iron and manganese, which preferentially accumulate in unsaturated zones of floodplain sediments.

The situation at the Koekemoerspruit is not an isolated occurrence. Many gold-mines are active in dolomitic areas, and it is expected that similar surface water - groundwater interactions and resultant diffuse contamination will be found at most of these mines. This situation necessitates the revision of water quality monitoring protocols.

\section{Acknowledgements}

The study was funded as part of a comparative research project conducted in Germany, Southern Africa and Australia by the German Academy of Natural Scientists Leopoldina (project no. BMBF-LPD 9801-17).

Frank Winde wishes to thank Mr S van Biljon (DWAF, Pretoria) and Mr F le Roux (DWAF, Boskop Dam) and his skilled team for their logistical and technical support in setting up the automatic gauging station.

\section{References}

DE BEER G (2000) Statistical Evaluation of Time Series from a Hydrological Research Project at the Koekemoerspruit. Final year unpublished project report. Potchefstroom University for CHE, Statistics.

DE BRUIN P (2000) Personal communication. Mine Water Manager at Margaret shaft and Buffelsfontein Gold Mine. July.

MATTHEß G and UBELL K (1990):Allgemeine Hydrogeologie. Grundwasserhaushalt. Lehrbuch der Hydrogeologie Bd. 1. Berlin, Stuttgart. 593 pp.

WINDE F (2003) Urankontamination von Fließgewässern - Prozessdynamik, Mechanismen und Steuerfaktoren. Untersuchungen zum Transport von gelöstem Uran in bergbaulich gestörten Landschaften unterschiedlicher Klimate. Habilitationsschrift, Universität Jena. 377 pp.

WINDE F, WADE P and VAN DER WALT IJ (2004a) Gold tailings as a source of water-borne stream contamination - The Koekemoerspruit (Klerksdorp gold field, South Africa) as a case study. Part I of III. Uranium migration along the aqueous pathway. Water $S A 30$ (2) 219226.

WINDE F, WADE P and VAN DER WALT IJ (2004b) Gold tailings as a source of water-borne stream contamination - The Koekemoerspruit (Klerksdorp gold field, South Africa) as a case study. Part III of III. Fluctuations of stream chemistry and their impacts on uranium mobility. Water SA 30 (2) 233-240. 